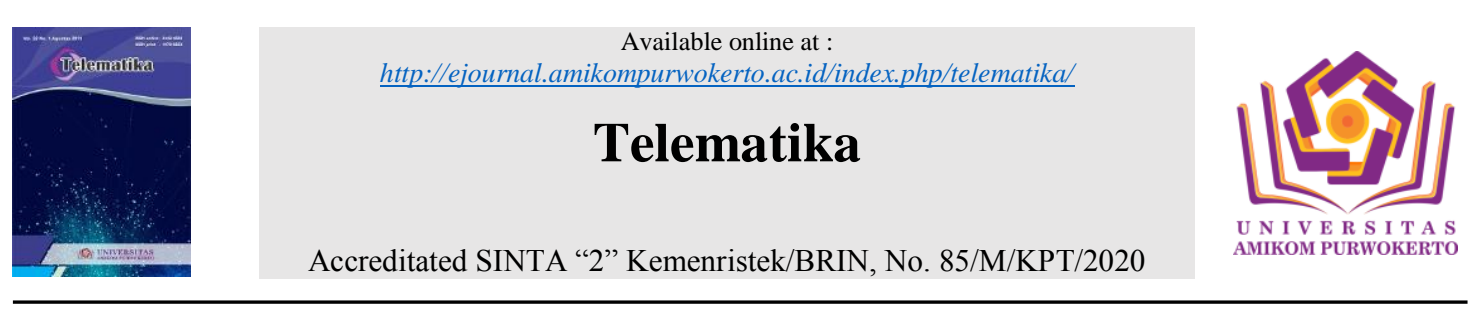

\title{
Image Quality Analysis of PNG Images on WhatsApp Messenger Sending
}

\author{
Fahmi Anwar', Abdul Fadlil ${ }^{2}$, Imam Riadi ${ }^{3}$ \\ ${ }^{1}$ Department of Informatics, Universitas Ahmad Dahlan \\ ${ }^{2}$ Department of Electrical Engineering, Universitas Ahmad Dahlan \\ ${ }^{3}$ Department of Information Systems, Universitas Ahmad Dahlan \\ Email : fahwar95@gmail.com ${ }^{1}$, fadlil@mti.uad.ac.id ${ }^{2}$,imam.riadi@is.uad.ac.id ${ }^{3}$
}

\begin{tabular}{l}
\hline A R T I C L E I N F O \\
\hline History of the article: \\
Received September 10, 2020 \\
Revised October 10, 2020 \\
Accepted December 15, 2020 \\
\\
\hline Keywords: \\
Analysis, \\
Compression, \\
Picture, \\
PNG, \\
WhatsApp
\end{tabular}

Correspondence:

Telepon: +62 (274) 563515

E-mail: fadlil@mti.uad.ac.id

\begin{abstract}
Technology is growing rapidly, especially in communication with various types of information services such as internet-based messages. One of the most popular internet-based messages in Indonesia is WhatsApp Messenger. WhatsApp is a chat application that can be used on many platforms. Message sending on WhatsApp is carried out end-to-end encryption from the sender to the message recipient. The sending of messages in PNG images is secured using end-to-end encryption and compressed according to predefined rules. This study analyzes Image Compression and Alpha channel in PNG by comparing PNG images before being sent with PNG images that have gone through the sending process on WhatsApp using the test-driven development (TDD) method. The analysis results contain comparisons based on the RMSE, SSIM, PSNR, and MD5 hash values. Delivery with a gallery image attachment type using an image transparent background changes to a white image background. While those with a background other than transparent have good image quality because it has a PSNR value of more than $35 \mathrm{~dB}$, and submissions with document attachment types do not experience changes in MD5 hash value and image quality.
\end{abstract}

\section{INTRODUCTION}

Information and communication technology in the world is growing rapidly, one of which is in Indonesia. There are various types of communication technologies, such as e-mail, chat, audio calls, video calls, instant messages, etc. The available information and communication technology devices also vary, such as laptops, tablets, cellphones, etc. Hardware and software can make interconnected with more diverse forms. The impact of different types of technology accessible to various groups results in a high level of smartphone use because it combines communication and mobility advantages. (O'Hara et al., 2014)

The WhatsApp application is the most used chat application globally, with more than 1.5 billion active users. WhatsApp has an image file sending feature that can be shared quickly, even if it is a large image file. WhatsApp can compress (compressing) uploaded images. The file upload process is a technique that is usually functionally required in applications for users (Chen et al., 2015). Messages sent on the WhatsApp Application use end-to-end security (Erlingsson et al., 2007) and validation in image file upload (Anwar et al., 2020b) like files that can be sent on WhatsApp, namely image files.

The image consists of various numbers arranged by having the light intensity value for each part (Johnson \& Jajodia, 1998). Images also have descriptions in a numerical form called pixels. Pixels are 
displayed horizontally from row to row, which has a color scheme. A color scheme has some bits known as bit depth, and it refers to the number of bits assigned to each pixel (Poornima \& Iswarya, 2013). Image formats that are often used on the internet are Graphics Interchange Format (GIF), Joint Photographic Experts Group (JPEG), and Portable Network Graphics (PNG) (Anwar et al., 2019). JPEG image files can be compressed or compressed using various image compression techniques, while PNG has an alpha channel or transparent values. Image compression produces a more compact image representation, thereby reducing the transmission of image storage. (Vijayvargiya et al., 2013)

Previous research on images such as the Error Level Analysis (ELA) technique on Forensicallybeta can be used to detect the authenticity of an image (Sulistyo et al., 2018) and validation using PNG metadata image files (Anwar et al., 2020a). Research on WhatsApp Messenger on Android devices produces database structure information with AES 192 encryption and the structure of stored storage files (Anglano, 2014). This study conducted a comparison of image quality or Image Quality Assessments. Image Quality Assessments compares metric modeling between the original (ideal) image and the distorted version, which aims to compare and evaluate the image processing algorithm is performance. Other measurements can use image quality measurements subjectively using human senses but these measurements or calculations are very difficult to do because the conditions of the assessment must depend on different human visions. (Riadi \& Nasrulloh, 2019) (Mohammadi et al., 2014)

\section{RESEARCH METHODS}

This study uses the test-driven development (TDD) method by making software components requirements as the basis for creating a series of test scenarios or test cases and trying to find errors in the data structure and functionality sent by the components. TDD is not a new technology but rather a trend that emphasizes test cases before source code generation. TDD flow can be seen in Figure 1. (Pressman \& Maxim, 2014)

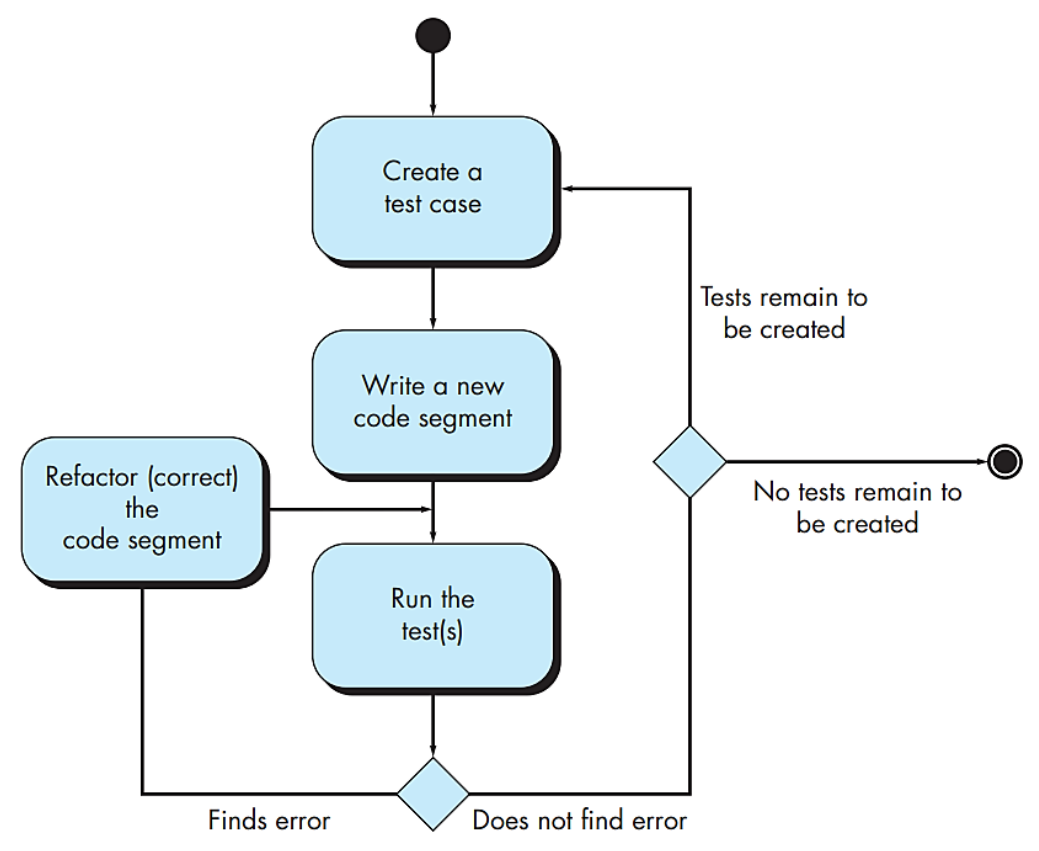

Figure 1. Test-driven development (TDD) method

The TDD process follows a simple procedure flow illustrated in Figure 1. Before the first small segment of code is generated, the programmer creates a test to run the code (to make the code fail). The 
code is then written to fulfill the test. If it passes, a new test is created for the next code segment to be developed. The process continues until the component is fully coded, and all tests run error-free. If any test finds an error, the existing code is corrected, and all tests built to that point are executed. This iterative flow continues until there are no tests left to make, implying that the component meets all the requirements specified for it.

The test scenario or test case consists of three types of backgrounds: transparent, white, and black, and several dimensions uploaded on the WhatsApp application. Figure 2 is then sent based on the process scenario as presented in Figure 3 and compared between the two images based on the MD5 checksum value and the image quality.

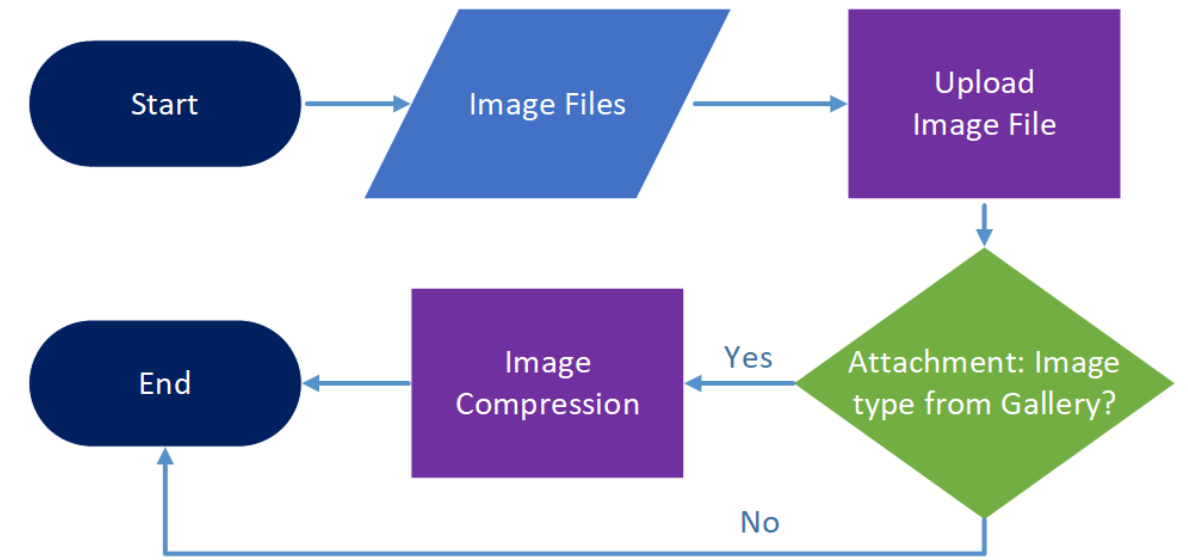

Figure 2. The Process of Uploading Images on WhatsApp

The results of the image that have been processed, such as the flow of the illustration in Figure 2. The calculation of image quality in compression is carried out by comparing the RMSE, SSIM, and PSNR values in Matlab.

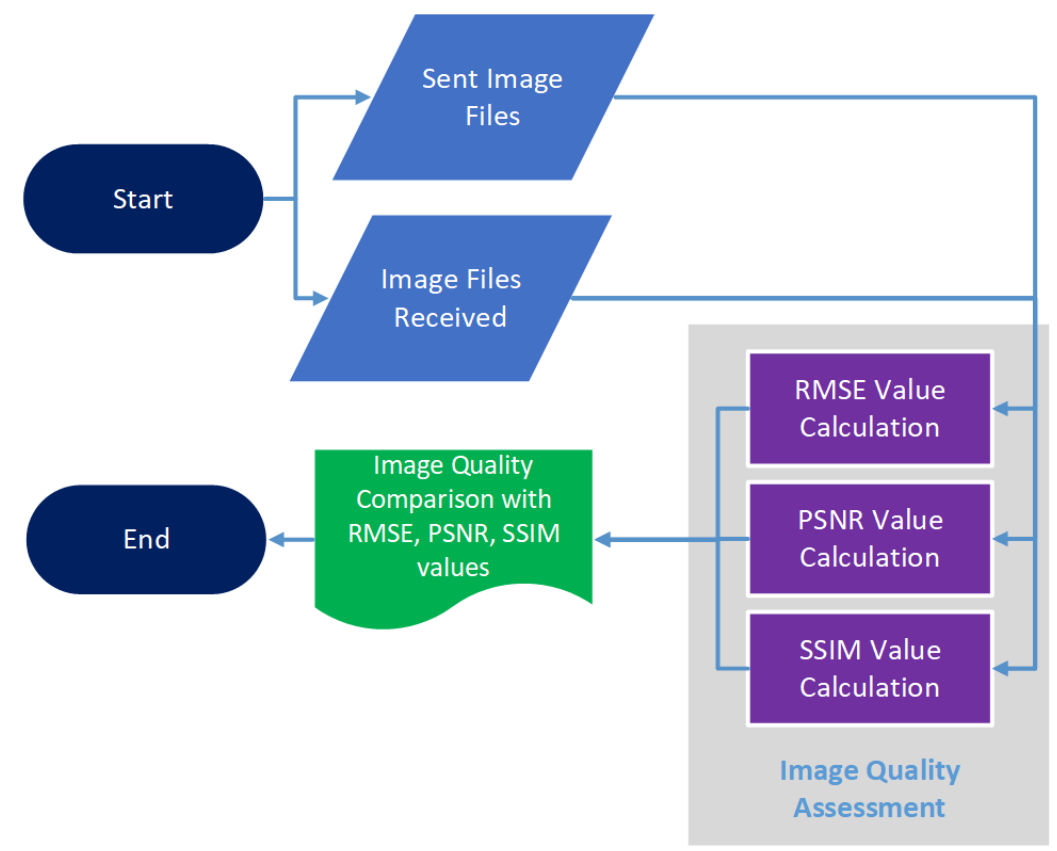

Figure 3. Image Quality Analysis Process

The Image Quality Assessments analysis process compares the sent image with the received image, as illustrated in Figure 3. The RMSE value is getting closer to 0, the better the image quality. SSIM values 
range from 0 to 1 ; if closer to 0 then better the image quality. While for PSNR, the greater the value, the closer the image processing results to the original (Mehra \& Scholar, 2016); if the PSNR value is above 35 or $40 \mathrm{~dB}$, the image quality is said to be good (Rajkumar \& Malathi, 2016).

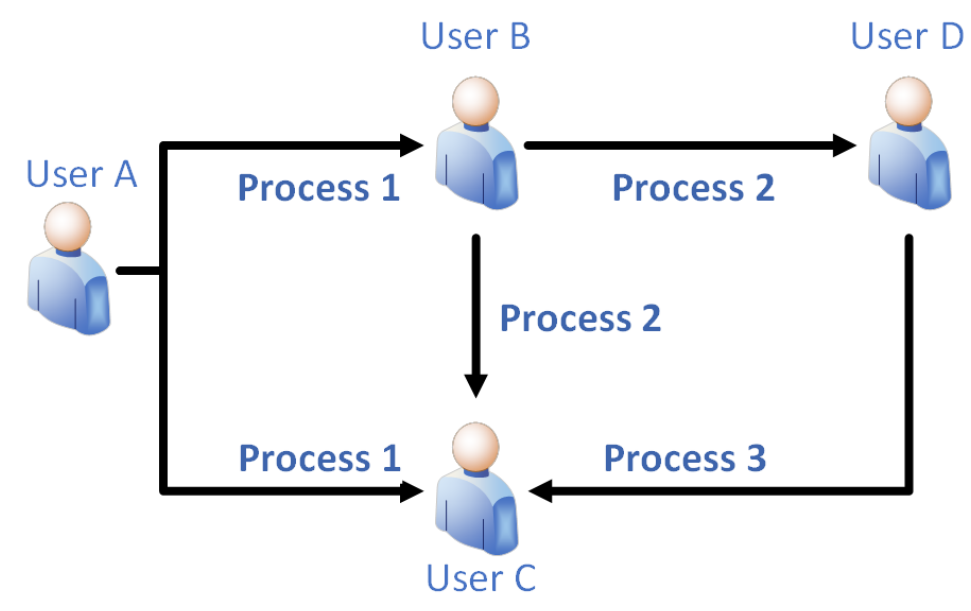

Figure 4. WhatsApp Image Sending Scenarios

The scenario in Figure 4 has several processes, such as Process 1 sending images from User A to User B and C, Process 2 sending images from User B to User C and D, then Process 3 sending images from User D to User C.

\section{Metadata}

Metadata contains information from a digital object. This information can be used to identify the type of digital camera, manufacturing time, etc. (Sari et al., 2016). The metadata information used includes the image dimension size (pixels) and the image file size (file size) to compare the sent image with the received image.

\section{Checksum MD5}

A checksum is a very long alphanumeric string that commonly uses algorithms such as MD5 or SHA-1. This very long alphanumeric string acts as a fingerprint for a particular file. A checksum is also a part of a file signature, such as a magic number used to ensure file integrity on transmission from one storage device to another that can cross the internet or only between two devices on the same network. (Zaenudin et al., 2018)

\section{Root-mean-square error (RMSE)}

Root-mean-square error (RMSE) is a commonly used error measurement technique to measure the difference between a predicted value and an actual value. This calculation evaluates the magnitude of the error with a perfect measure of accuracy used to make a difference in forecast errors from different estimators for certain variables (Sara et al., 2019) as in Equation 1.

$$
R M S E=\sqrt{\frac{1}{m \times n} \sum_{i=0}^{n-1} \sum_{j=0}^{m-1}[f(i, j)-g(i, j)]^{2}}
$$

where:

RMSE is the root mean square error value

$\mathrm{m} \quad$ is the image height (in pixels)

$\mathrm{f}(\mathrm{i}, \mathrm{j}) \quad$ is the pixel value in the coordinates $(i, j)$ in the image $f$ as a reference 
$\mathrm{n} \quad$ is the image width (in pixels)

$\mathrm{g}(\mathrm{i}, \mathrm{j}) \quad$ is the pixel value at the coordinates $(\mathrm{i}, \mathrm{j})$ of the image $\mathrm{g}$ as being compared

\section{Structural Similarity Index Measurement (SSIM)}

Structural Similarity Index Measurement (SSIM) is a perception-based model in which image degradation is considered perceptual changes in structural information based on other essential perceptions such as luminance masking, contrast masking, etc. The term structural information emphasizes highly interdependent pixels or spatially closed pixels. These highly interdependent pixels refer to more critical information about visual objects in the image domain. Luminance masking is the less visible part of the image distortion at the edges of the image. The measurement compares the similarity between the two original and recovered images (Bharti et al., 2009) as in Equation 2.

$$
S S I M=\frac{\left(2 \mu_{x} \mu_{y}+c_{1}\right)\left(2 \sigma_{x y}+c_{2}\right)}{\left(\mu_{x}^{2}+\mu_{y}^{2}+c_{1}\right)\left(\sigma_{x}^{2}+\sigma_{y}^{2}+c_{2}\right)}
$$

Where :

$\begin{array}{ll}\text { SSIM } & \text { is the Structural Similarity value of the image } \\ \mathrm{x} & \text { is the width coordinate of the image dimension } \\ \mu_{\mathrm{x}} & \text { is the long coordinate of the image dimension } \\ \mu_{\mathrm{y}} & \text { is the mean of } \mathrm{x} \\ \sigma_{x y} & \text { is the mean of } \mathrm{y} \\ \sigma_{x}^{2} & \text { is a variant of } \mathrm{x} \\ \sigma_{y}^{2} & \text { is the variant } \mathrm{y} \\ \mathrm{k}_{1} & \text { is } 0.01 \\ \mathrm{k}_{2} & \text { is } 0.03 \\ \mathrm{~L} & \text { is the dynamic range }\left(2^{8}-1\right) /(255) \\ \mathrm{c}_{1} & \text { is }\left(\mathrm{k}_{1} \mathrm{~L}\right)^{2} /(0.01 \times 255)^{2} \\ \mathrm{c}_{2} & \text { is }\left(\mathrm{k}_{2} \mathrm{~L}\right)^{2} /(0.03 \times 255)^{2}\end{array}$

\section{Peak signal-to-noise ratio (PSNR)}

The peak signal to noise ratio (PSNR) calculates the ratio between the maximum signal strength and the noise or distortion strength that affects the quality of the representation. The ratio between these two images is calculated in decibels (dB). PSNR is usually calculated as a logarithmic term for the decibel scale because it has an extended dynamic range. This dynamic range varies between the largest and the smallest values, which can be changed by the quality (Ai Munandar et al., 2011) as in Equations 3 and 4.

$$
M S E=\frac{1}{m \times n} \sum_{i=0}^{n-1} \sum_{j=0}^{m-1}[f(i, j)-g(i, j)]^{2}
$$

Where :

MSE is the Mean Square Error value

$\mathrm{m} \quad$ is the image height (in pixels)

$f(i, j) \quad$ is the pixel value in the coordinates $(i, j)$ in the image $f$ as a reference

$\mathrm{n} \quad$ is the image width (in pixels)

$\mathrm{g}(\mathrm{i}, \mathrm{j}) \quad$ is the pixel value at the coordinates $(\mathrm{i}, \mathrm{j})$ of the image $\mathrm{g}$ as being compared 
After getting the MSE value from Equation 3, the results are entered into the PSNR formula (Kaushik \& Gupta, 2012) as in Equation 4.

$$
\begin{aligned}
& \text { PSNR }=10 \cdot \log _{10}\left(\frac{M A X_{I}^{2}}{M S E}\right) \\
& \text { PSNR }=20 \cdot \log _{10}\left(\frac{M A X_{I}}{\sqrt{M S E}}\right) \\
& \text { PSNR }=20 \cdot \log _{10}\left(M A X_{I}\right)-10 \cdot \log _{10}(M S E)
\end{aligned}
$$

Where :

PSNR is the image PSNR value (in $\mathrm{dB}$ )

MSE is the MSE value

$M A X_{I} \quad$ is the maximum pixel value (255)

\section{RESULTS AND DISCUSSION}

\section{Image Comparison using MD5 Checksum}

The MD5 checksum calculation from User A (Sender) produces a hash value md5 ad52ac5e270681a961dd9dc6a7013494 then the image is sent to other users using two types of sending attachments, namely gallery images, and documents, as in Figure 5.

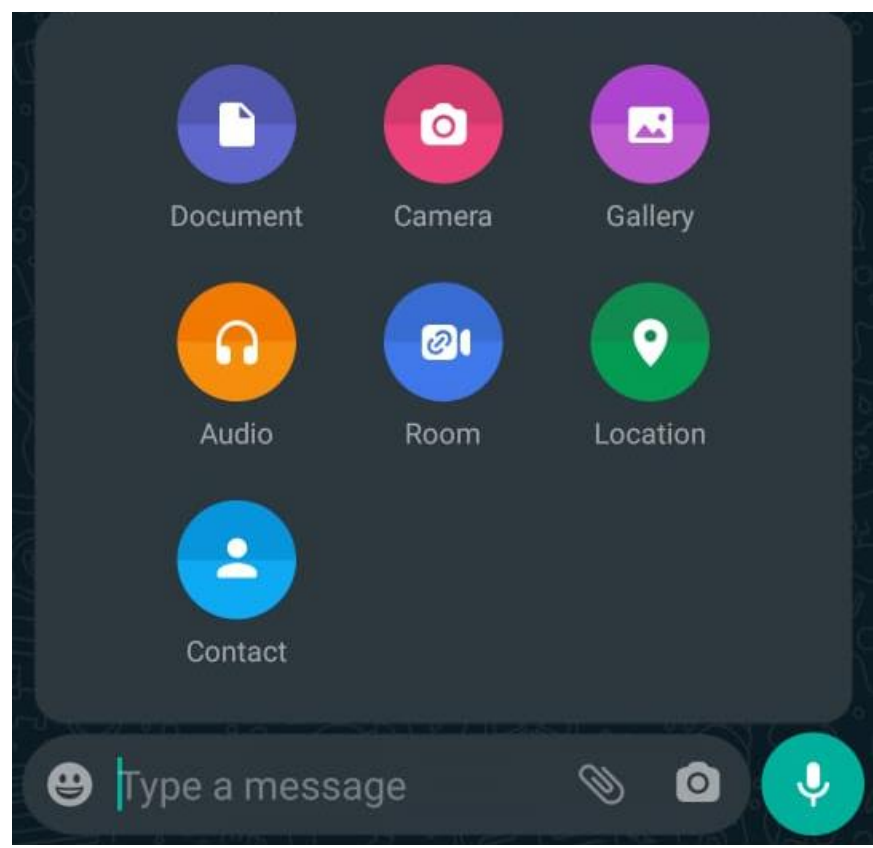

Figure 5. Types of File Sending on WhatsApp

Images received by user B from User A using document type have the same MD5 checksum value as User A, namely ad52ac5e270681a961dd9dc6a7013494. User B forwards the file to user C produces the same MD5 value while the files that User B receives from User A uses type. The gallery image attachment has a hash value of a9e0537fb2231c5e8e $0 \mathrm{fbab} 1205 \mathrm{~d} 188 \mathrm{f}$. User B sends back to

User $C$ with the forward feature and returns the same MD5 value a9e0537fb2231c5e8e0fbab1205d188f. The results of checking the MD5 checksum in the figure are presented in Table 1. 
Table 1 . The result of checking the MD5 checksum on image sending

\begin{tabular}{ccc}
\hline No. & MD5 & Compressed \\
\hline 1 & ad52ac5e270681a961dd9dc6a7013494 & No \\
2 & a9e0537fb2231c5e8e0fbab1205d188f & Yes \\
3 & a9e0537fb2231c5e8e0fbab1205d188f & Yes \\
4 & ad52ac5e270681a961dd9dc6a7013494 & No \\
\hline
\end{tabular}

Information :

Number $1=$ Forwarder Document

Number $2=$ Forwarder Image

Number 3 = Document shipment via Picture

Number 4 = Document shipment via Document

Table 1 shows that sending image files using the uncompressed document attachment type while sending image files using gallery images will be compressed.

\section{Image Comparison using Image Quality}

Image quality comparisons using RMSE, SSIM, and PSNR calculations were performed using image samples with transparent, white, and black backgrounds and several dimensional sizes. Image quality comparison using the Matlab application with the program code presented in Program Code 1.

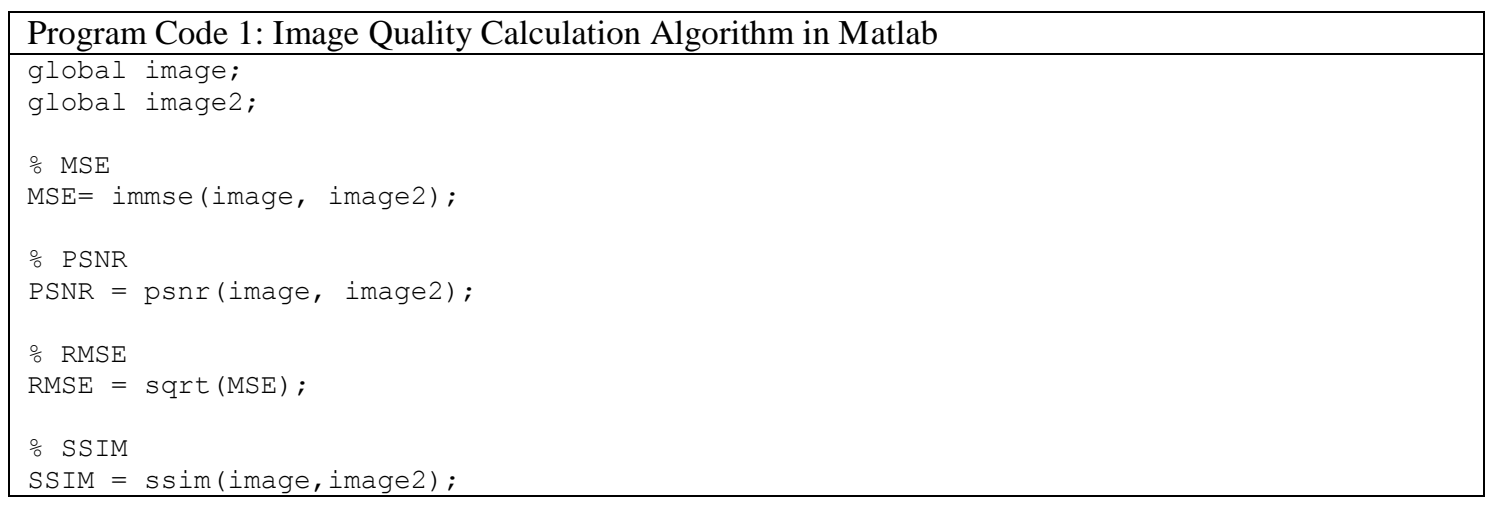

The Matlab algorithm in Program Code 1 calculates the image quality with PSNR, RMSE, and SSIM parameters by comparing two images with the same resolution.

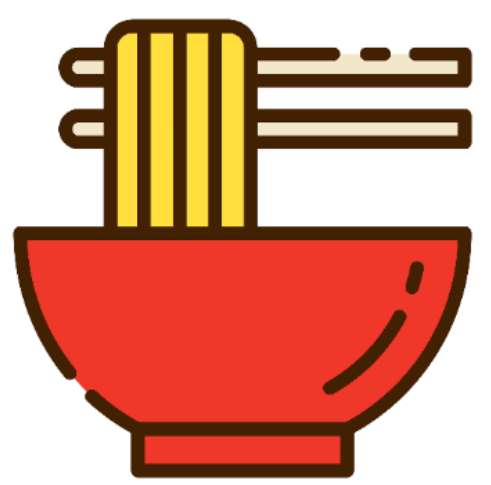

Figure 6. Sample PNG image with transparent background

Figure 6 is a PNG file with a transparent background that is processed on WhatsApp sending by going through size and resolution compression. The results of sending PNG files with a transparent background on WhatsApp are presented in Table 2. 
Table 2. The result of sending a PNG image with a transparent background

\begin{tabular}{rrrrr}
\hline No & $\begin{array}{c}\text { Dimension } \\
\text { Input (pixels) }\end{array}$ & $\begin{array}{c}\text { File size } \\
\text { input }(\text { KB) }\end{array}$ & $\begin{array}{c}\text { Dimension } \\
\text { output (pixels) }\end{array}$ & $\begin{array}{c}\text { File size } \\
\text { output }(\text { KB })\end{array}$ \\
\hline 1 & $32 \times 32$ & 3,22 & $32 \times 32$ & 1,72 \\
\hline 2 & $64 \times 64$ & 5,00 & $64 \times 64$ & 3,59 \\
\hline 3 & $128 \times 128$ & 9,06 & $128 \times 128$ & 7,79 \\
\hline 4 & $256 \times 256$ & 16,60 & $256 \times 256$ & 19,40 \\
\hline 5 & $512 \times 512$ & 32,10 & $512 \times 512$ & 46,50 \\
\hline 6 & $1024 \times 1024$ & 66,20 & $1024 \times 1024$ & 105,00 \\
\hline 7 & $2048 \times 2048$ & 143,00 & $1280 \times 1280$ & 134,00 \\
\hline 8 & $4096 \times 4096$ & 307,00 & $1280 \times 1280$ & 132,00 \\
\hline 9 & $8192 \times 8192$ & 719,00 & $1280 \times 1280$ & 133,00 \\
\hline
\end{tabular}

Table 2 contains data on comparing image input and image output after going through the sending process on WhatsApp on a PNG sample with a transparent background. After sending it to other users, the image has a maximum dimension of $1280 \times 1280$ pixels, and the largest file size is the input image with a dimension of 2048 x 2048 pixels of 134KB. RMSE, SSIM, and PSNR calculations can only be done in figures 1 to 6 because the dimensions of the input and output dimensions are the same, or there is no change in dimensions so that the values can be compared. The results of calculating the quality of PNG images on WhatsApp with transparent background are presented in Table 3.

Table 3. The results of the calculation of the comparison of PNG images with a transparent background

\begin{tabular}{rrrrr}
\hline No & $\begin{array}{c}\text { Dimension } \\
\text { (pixels) }\end{array}$ & RMSE & SSIM & PSNR \\
\hline 1 & $32 \times 32$ & 29.5151 & 0.728466 & 6.627258 \\
\hline 2 & $64 \times 64$ & 29.3112 & 0.747613 & 6.569006 \\
\hline 3 & $128 \times 128$ & 28.6370 & 0.762760 & 6.650411 \\
\hline 4 & $256 \times 256$ & 27.7087 & 0.777700 & 6.832774 \\
\hline 5 & $512 \times 512$ & 27.5872 & 0.780742 & 6.816153 \\
\hline 6 & $1024 \times 1024$ & 27.5092 & 0.782141 & 6.824240 \\
\hline
\end{tabular}

Table 3 shows that PNG image quality with a transparent background has low image quality, which can be seen from the RMSE value below 30 and PSNR below $40 \mathrm{~dB}$. According to SSIM calculations, it is below 0.8 . Low quality of transparent backgrounds due to changing the alpha channel or transparent to white color.

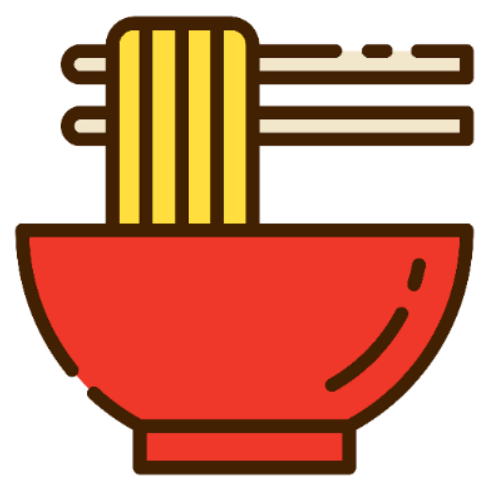

Figure 7. Sample PNG image with a white background 
Figure 7 is a PNG sample that was processed on sending the WhatsApp application by going through size and resolution compression. The results of sending PNG with a white background on the WhatsApp application are presented in Table 4.

Table 4. Result of sending PNG image with white background

\begin{tabular}{rrrrr}
\hline No & $\begin{array}{c}\text { Dimension } \\
\text { Input (pixels) }\end{array}$ & $\begin{array}{c}\text { File size } \\
\text { input }(\text { KB })\end{array}$ & $\begin{array}{c}\text { Dimension } \\
\text { output (pixels) }\end{array}$ & $\begin{array}{c}\text { File size } \\
\text { output }(\text { KB })\end{array}$ \\
\hline 1 & $32 \times 32$ & 3,02 & $32 \times 32$ & 1,72 \\
\hline 2 & $64 \times 64$ & 4,69 & $64 \times 64$ & 3,61 \\
\hline 3 & $128 \times 128$ & 8,17 & $128 \times 128$ & 7,76 \\
\hline 4 & $256 \times 256$ & 15,70 & $256 \times 256$ & 20,10 \\
\hline 5 & $512 \times 512$ & 26,90 & $512 \times 512$ & 46,50 \\
\hline 6 & $1024 \times 1024$ & 53,90 & $1024 \times 1024$ & 104,00 \\
\hline 7 & $2048 \times 2048$ & 115,00 & $1280 \times 1280$ & 135,00 \\
\hline 8 & $4096 \times 4096$ & 258,00 & $1280 \times 1280$ & 132,00 \\
\hline 9 & $8192 \times 8192$ & 646,00 & $1280 \times 1280$ & 133,00 \\
\hline
\end{tabular}

Table 4 compares the image input and output sample PNG images on a white background after going through the sending process on WhatsApp. The maximum dimension obtained after the image is sent to other users is $1280 \times 960$ pixels, and the largest file size is image number 7 , which is 135 KB. RMSE, SSIM, and PSNR calculations can only be done on image dimensions 1 to 6 because the input and output dimensions are the same so that the values can be compared. The results of calculating image quality on WhatsApp using PNG with a white background are presented in Table 5.

Table 5. The Results of the Calculation of the Comparison of The PNG Image Value Against a White Background

\begin{tabular}{rrrrr}
\hline No & $\begin{array}{c}\text { Dimension } \\
\text { (pixels) }\end{array}$ & RMSE & SSIM & PSNR \\
\hline 1 & $32 \times 32$ & 1.7637 & 0.999519 & 38.908526 \\
\hline 2 & $64 \times 64$ & 1.2044 & 0.997697 & 41.295005 \\
\hline 3 & $128 \times 128$ & 0.8469 & 0.999185 & 43.825704 \\
\hline 4 & $256 \times 256$ & 0.6682 & 0.999150 & 46.067807 \\
\hline 5 & $512 \times 512$ & 0.4414 & 0.999777 & 48.904808 \\
\hline 6 & $1024 \times 1024$ & 0.3168 & 0.999903 & 52.335478 \\
\hline
\end{tabular}

Table 5 shows that the dimensions closest to the maximum dimensions get better image quality than PNG images with a transparent background, which can be seen from the best RMSE value of 0.3168. The best SSIM value is close to 1 at 0.999903 , and PSNR above $40 \mathrm{~dB}$ is in the dimensions of 1024 x 1024 pixels.

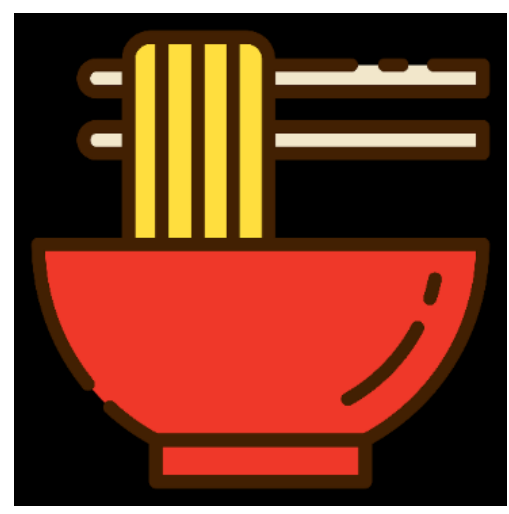

Figure 8. Sample Image PNG with black background 
Figure 8 is a sample PNG image that is processed in sending images on WhatsApp by going through size and resolution compression. The results of sending PNG images with a black background on WhatsApp are presented in Table 6.

Table 6. Result of sending PNG with black background

\begin{tabular}{rrrrr}
\hline No & $\begin{array}{c}\text { Dimension } \\
\text { Input (pixels) }\end{array}$ & $\begin{array}{c}\text { File size } \\
\text { input }(\text { KB })\end{array}$ & $\begin{array}{c}\text { Dimension } \\
\text { Output (pixels) }\end{array}$ & $\begin{array}{c}\text { File size } \\
\text { output }(\text { KB })\end{array}$ \\
\hline 1 & $32 \times 32$ & 2,89 & $32 \times 32$ & 1,62 \\
\hline 2 & $64 \times 64$ & 4,39 & $64 \times 64$ & 3,38 \\
\hline 3 & $128 \times 128$ & 7,57 & $128 \times 128$ & 7,46 \\
\hline 4 & $256 \times 256$ & 14,10 & $256 \times 256$ & 19,50 \\
\hline 5 & $512 \times 512$ & 24,70 & $512 \times 512$ & 45,10 \\
\hline 6 & $1024 \times 1024$ & 49,80 & $1024 \times 1024$ & 102,00 \\
\hline 7 & $2048 \times 2048$ & 106,00 & $1280 \times 1280$ & 130,00 \\
\hline 8 & $4096 \times 4096$ & 241,00 & $1280 \times 1280$ & 123,00 \\
\hline 9 & $8192 \times 8192$ & 607,00 & $1280 \times 1280$ & 124,00 \\
\hline
\end{tabular}

Table 6 shows the comparison of image input and image output in a PNG sample with a black background after going through the sending process on WhatsApp. The sample PNG image with a black background after being sent to other users has a maximum dimension of $1280 \times 720$ pixels, and the largest file size is image number 7, $130 \mathrm{~KB}$. RMSE, SSIM, and PSNR calculations can only be done on image dimensions 1 to 6 because the input and output dimensions are the same so that the values can be compared. The results of image quality calculations on WhatsApp with PNG images on a black background are presented in Table 7.

Table 7. Calculation Results Comparison of PNG Image with Black Background

\begin{tabular}{rrrrr}
\hline No & $\begin{array}{c}\text { Dimension } \\
\text { (pixels) }\end{array}$ & RMSE & SSIM & PSNR \\
\hline 1 & $32 \times 32$ & 2.0246 & 0.984701 & 39.660392 \\
\hline 2 & $64 \times 64$ & 1.3865 & 0.991911 & 41.648371 \\
\hline 3 & $128 \times 128$ & 0.9883 & 0.997863 & 44.102851 \\
\hline 4 & $256 \times 256$ & 0.7630 & 0.999239 & 46.532767 \\
\hline 5 & $512 \times 512$ & 0.4992 & 0.999551 & 49.517204 \\
\hline 6 & $1024 \times 1024$ & 0.3524 & 0.999683 & 53.091645 \\
\hline
\end{tabular}

Table 7 shows that the dimensions closest to the maximum dimensions get better image quality, which can be seen from the smallest RMSE value of 2.0246 while the largest is 0.3524 , then the smallest PSNR value is 39 and the largest 53. The best SSIM calculation for image quality is $1024 \times$ 1024 pixels with dimensions because it has the most excellent value of 0.999683 .

\section{CONCLUSIONS AND RECOMMENDATIONS}

Based on the test results, PNG images sent using attachments with the image type will be compressed, while attachments with document types are not compressed (uncompressed). Additionally, forwarded PNG images do not change MD5 hash values or checksums. In the study case, larger dimensions than the maximum dimensions of $1280 \times 1280$ pixels will be reduced to reach the maximum dimensional resolution by paying attention to the ratio of dimensions. Simultaneously, the dimensions of the image that are less than the maximum dimensions will not be reduced in dimensions (only the file size value will be reduced). Image quality on PNG images with transparent backgrounds has low quality seen from RMSE less than $40 \mathrm{~dB}$, PSNR below 0.9, and SSIM below 38 while PNG images with black and white backgrounds 
have good image quality seen from RMSE above $40 \mathrm{~dB}$, PSNR above 38, and SSIM above 0.9. Further research is suggested to use the method of calculating image quality and other image file types.

\section{ACKNOWLEDGEMENT}

This research is supported by Direktorat Riset dan Pengabdian Masyarakat, Direktorat Jenderal Penguatan Riset dan Pengembangan Kementerian Riset, Teknologi, dan Pendidikan Tinggi Republik Indonesia. Surat Kontrak Pelaksanaan Penelitian Kementerian Riset dan Teknologi/Badan Riset dan Inovasi Nasional (KEMENRISTEK/BRIN) Tahun Tunggal Tahun Anggaran 2020 Nomor: PTM019/SKPP.TT/LPPM UAD/VI/2020.

\section{REFERENCES}

Ai Munandar, T., Adelvin L, M., \& Santoso, A. J. (2011). Analisa Psnr, Rasio Kompresi Warna Dan Mse Terhadap Kompresi Image Menggunakan 31 Fungsi Wavelet. 2(db 1), 71-81.

Anglano, C. (2014). Forensic analysis of whats app messenger on Android smartphones. Digital Investigation, 11(3), 201-213. https://doi.org/10.1016/j.diin.2014.04.003

Anwar, F., Fadlil, A., \& Riadi, I. (2020a). Analisis Validasi Image PNG File Upload menggunakan Metadata pada Aplikasi Berbasis Web. Edu Komputika Journal, 7(1), 10-15. https://doi.org/10.15294/edukomputika.v7i1.38722

Anwar, F., Fadlil, A., \& Riadi, I. (2020b). Validation Analysis of Scalable Vector Graphics ( SVG ) File Upload using Magic Number and Document Object Model ( DOM ). (IJACSA) International Journal of Advanced Computer Science and Applications, 11(11), 255-262. https://dx.doi.org/10.14569/IJACSA.2020.0111133

Anwar, F., Fadlil, A., \& Riadi, I. (2019). Analisa Keamanan Image JPEG File Upload Menggunakan Metadata dan GD Graphic Library Pada Aplikasi Berbasis Web. In U. Krisnadwipayana (Ed.), Seminar Nasional Teknologi Fakultas Teknik Universitas Krisnadwipayana (pp. 479-487). Universitas Krisnadwipayana.

Bharti, P., Gupta, S., \& Bhatia, R. (2009). Comparative analysis of image compression techniques: A case study on medical images. ARTCom 2009 - International Conference on Advances in Recent Technologies in Communication and Computing, 820-822. https://doi.org/10.1109/ARTCom.2009.88

Chen, H., Zhang, L. J., Hu, B., Long, S. Z., \& Luo, L. H. (2015). On Developing and Deploying Large-File Upload Services of Personal Cloud Storage. Proceedings - 2015 IEEE International Conference on Services Computing, SCC 2015, 371-378. https://doi.org/10.1109/SCC.2015.58

Erlingsson, U., Livshits, B., \& Xie, Y. (2007). End-to-end Web Application Security. Proceedings of the 11th Workshop on Hot Topics in Operating Systems (HotOS'07), San Diego, CA, 2-7. https://www.microsoft.com/en-us/research/publication/end-to-end-web-application-security/

Johnson, N. F., \& Jajodia, S. (1998). Exploring steganography: Seeing the unseen. Computer, 31(2), 2634. https://doi.org/10.1109/MC.1998.4655281

Kaushik, A., \& Gupta, M. (2012). Analysis of Image Compression Algorithms. International Journal of Engineering Research and Applications, 2(2), 773-779.

Mehra, R., \& Scholar, M. E. (2016). Estimation of the Image Quality under Different Distortions. 5(17291), 17291-17296. https://doi.org/10.18535/ijecs/v5i7.20

Mohammadi, P., Ebrahimi-moghadam, A., \& Shirani, S. (2014). Subjective and Objective Quality Assessment of Image : A Survey. June, 1-50.

O’Hara, K., Massimi, M., Harper, R., Rubens, S., \& Morris, J. (2014). Everyday dwelling with WhatsApp. Proceedings of the ACM Conference on Computer Supported Cooperative Work, CSCW, 11311143. https://doi.org/10.1145/2531602.2531679

Poornima, R., \& Iswarya, R. J. (2013). An Overview Of Image Steganography. International Journal of Computer Science \& Engineering Survey, 4(1), 23-31. 
Pressman, R. S., \& Maxim, B. R. (2014). Software Engineering : a practitioner's approach (8th ed.). McGraw-Hill Education.

Rajkumar, S., \& Malathi, G. (2016). A Comparative Analysis on Image Quality Assessment for Real Time Satellite Images. 9(September). https://doi.org/10.17485/ijst/2016/v9i34/96766

Riadi, I., \& Nasrulloh, I. M. (2019). Analisis Forensik Solid State Drive (SSD) menggunakan Framework GRR Rapid Response Forensic. 6(5), 509-518. https://doi.org/10.25126/jtiik.201961516

Sara, U., Akter, M., \& Uddin, M. S. (2019). Image Quality Assessment through FSIM, SSIM, MSE and PSNR-A Comparative Study. Journal of Computer and Communications, 07(03), 8-18. https://doi.org/10.4236/jcc.2019.73002

Sari, T., Riadi, I., \& Fadlil, A. (2016). Forensik Citra untuk Deteksi Rekayasa File Menggunakan Error Level Analysis. Annual Research Seminar 2016, 2(1), 133-138. http://ars.ilkom.unsri.ac.id

Sulistyo, W. Y., Riadi, I., \& Yudhana, A. (2018). Analisis Deteksi Keaslian Citra Menggunakan Teknik. 2018(November), 154-159.

Vijayvargiya, G., Silakari, S., \& Pandey, R. (2013). A Survey: Various Techniques of Image Compression. 11(10). http://arxiv.org/abs/1311.6877

Zaenudin, Sugiantoro, B., \& Prayudi, Y. (2018). Metadata Forensik Untuk Analisis Korelasi Bukti Digital. $10(1), 85-89$. 